\title{
DETEKSI BOLA MENGGUNAKAN KOMBINASI METODE FILTER WARNA DAN BENTUK PADA ROBOT SOCCER
}

\author{
A Suheryadi ${ }^{1 凶}$, W Permana Putra ${ }^{2}$, M Lukman Sifa ${ }^{3}$, D Fathin ${ }^{4}$ \\ 1,2,3,4 Teknik Infomatika, Politeknik Negeri Indramayu, Indramayu

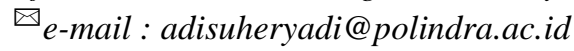

\begin{abstract}
Robot soccer is a combination of sports, robotics technology, and multi agent system, to achieve goals. Besides requiring individual intelligence, it also requires the ability to work together between individuals. The main problem in robot soccer is detecting objects in the form of balls. These problems include varying lighting that produces shadows from the ball, there are objects similar to balls, as well as realtime detection. Ease and lightweight program implementation are also needed in detecting the ball so that it is easy to implement on embedded systems. Computer vision technology helps robot soccer in detecting balls.Therefore, an alternative process is proposed to detect the ball using a combination of color filters and the shape or contour of the object. The results obtained from the experiments showed relatively effective in object detection, with a recall value of $90,69 \%$.
\end{abstract}

Keywords: Robot Soccer, Computer Vision, Ball Detection, Color Filter, Contour

\begin{abstract}
Abstrak
Robot soccer merupakan perpaduan antara olah raga, teknologi robotika, dan multi agent system, untuk mencapai tujuan, selain membutuhkan kecerdasan individu, juga menuntut kemampuan kerja sama antar individu. Masalah utama pada robot soccer adalah dalam pendektesian objek berupa bola. Permasalahan tersebut diantaranya adalah pencahayaan yang bervariasi yang menghasilkan bayangan dari bola, terdapat objek yang serupa dengan bola, serta real-time deteksi. Teknologi computer vision membantu robot soccer dalam mendeteksi bola. Kemudahan dan implementasi program yang ringan juga dibutuhkan dalam mendeteksi bola sehingga mudah untuk diimplementasikan pada embedded system. Oleh karenanya, diusulkan sebuah alternative proses dalam mendeteksi bola menggunakan penggabungan antara filter warna dan bentuk atau kontur dari objek. Hasil yang didapat dari percobaan menunjukan relative efektif dalam pendeteksian objek, dengan nilai recall sebesar 90,69\%.
\end{abstract}

Kata kunci: Robot Soccer, Computer Vision, Deteksi Bola, Filter Warna, Kontur

\section{Pendahuluan}

Computer vision merupakan teknologi populer pada automasi pengindraan robot. Banyak penelitian computer vision yang dimanfaatkan oleh robot dalam berbagai kegunaan diantaranya outomasi robot industri [1] dan robot kompetisi [2]. Perkembangan teknologi dalam revolusi industri 4.0 mengarah pada cyberphysical production system (CPS), teknologi otomatisasi, pertukaran data, dan manufaktur, memberikan motivasi lebih dekat pada outomasi robot dalam menyelesaikan persoalan indusrti [3]. Outomasi robot dalam bidang industri membutuhkan pengindraan visual untuk mengidentifikasi gerak, pemetaan, penentuan lokasi, deteksi hambatan, serta menemukan bagian-bagian pekerjaan[4]. Disisi lain penelitian yang dikembangkan dalam kompetisi robot berorientasi pada hardware, mekanik, komunikasi dan pengindraan dari robot. Pengindraan pada robot menjadi salah satu topik penelitian yang populer.

Teknologi computer vision merupakan teknologi pengindraan pada robot, digunakan dalam berbagai kompetisi diantaranya RoboCup Soccer [5], RoboCup Rescue [6], RoboCup @ Home [7], dan RoboCup Industrial [8]. Robot simulasi hingga robot humanoid ukuran 
penuh yang bersaing dalam sepak bola dikompetisikan pada robocup soccer. Penelitian yang berkaitan dengan vision pada robot soccer berkaitan dengan deteksi dan pelacakan object. Objek utama yang diamati oleh robot soccer adalah bola, dimana kendala yang dihadapi dalam pengamatan bola tersebut diantaranya adalah oklusi, bayangan yang menggangu pengamatan, objek serupa dengan bola baik dari warna maupun bentuk, serta pemrosesan real-time.

Deteksi bola menjadi faktor penting keberhasilan robot soccer dalam pertandingannya. Metode pengamatan bola telah diusulkan dalam berbagai penelitian dengan berbagai teknik, baik berhubungan langsung dengan robot soccer maupun video soccer analysis. Deteksi bola menggunakan informasi warna telah diteliti oleh [9]. Rahman dan Widodo menggunakan kamera yang terpasang pada robot untuk mengdeteksi dan melacak bola melalui model warna Hue-Saturation-Lightness (HSL) yang dilakukan pada setiap frame. Penelitian lainnya menggunakan algoritma viola jones, tanpa informasi warna [10] Beberapa algoritma lainnya yang digunakan untuk mengenali objek pada robot adalah deteksi tepi dan Blob Detection, seperti yang dilakukan pada penelitian [11]. Shah dkk [12] mengkombinasikan ekstraksi warna menggunakan HSV dan bentuk untuk mendeteksi bola. Dalam melacak pergerakan bola Shah dkk, menggunakan filter yang memungkinkan melacak pergerakan bola menggunakan haugh transform seperti yang diusulkan oleh Eric Gabriel et. al [13]. Dalam penelitian lainnya, Kalman filter digunakan untuk mendeteksi serta mentracking object yang bergerak [14].

Menentukan posisi dan size bola dalam mendeteksi dan melacak pergerakan bola menjadi topik yang menarik dalam penelitian. Hal ini dikarenakan keterbatasan yang ada pada robot soccer dimana kemampuan prosesor yang terbatas, sehingga dalam memproses video resolusi tinggi akan menjadi kendala. Selain itu, mendeteksi objek berupa bola akan menghasilkan lingkaran yang kecil apalagi jika terkena gangguan lingkungan yang ada. Hal ini menjadi tread of ball detection and tracking pada robot soccer, yang harus dijembatani oleh optimasi algoritma, salah satunya dengan mengoptimalkan dalam pengenalan tepi dari bola.

Dalam penelitian yang ditulis oleh Vijayarani dan Vinupriya [15] menyatakan deteksi tepi Canny menghasilkan akurasi yang cukup tinggi dalam mendeteksi suatu tepi dan waktu eksekusi. Dalam implementasinya, Vijayarani menggunakan kamera sebagai pemroses berbasis video realtime. Dari pemaparan diatas, dalam penelitian ini diusulkan penggabungan informasi warna, bentuk objek menggunakan deteksi tepi sebagai fitur

\section{Metode Penelitian}

Tahapan dalam usulan penelitian ini terbagi menjadi lima proses besar yaitu Object Sampling, Color Filtering, Blob Filtering, Contour Filtering, dan Object Determining, ditunjukan pada Gambar 1. Metode dari penelitian dibangun menggunakan bahasa pemrograman python, library opencv dan diterapkan pada embedded device. Embedded device yang digunakana adalah 6. Odroid XU4 Octa Core. Pada penelitian ini juga diujikan sebanyak 12 record video yang diambil melalui kamera yang tertanam pada robot soccer.

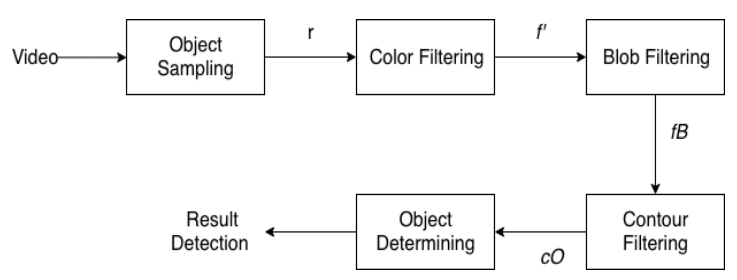

Gambar 1. Diagram proses dari sistem yang diusulkan 
Proses pertama yaitu object sampling merupakan proses menentukan interest object dari sistem yang diamati. Hasil dari sampling object ini adalah $r$ yang merupakan range warna dari bola. Struktur warna yang digunakan dalam penelitian ini adalah RGB (Red Green Blue). Selanjutnya, $r$ digunakan sebagai input dari proses color filtering, dimana color filtering merupakan proses penentuan kandidat dari interest object dan menghasilkan $f^{\prime} . \quad f^{\prime}$ adalah frame yang telah terfilter menggunakan filter warna. Dalam $f^{\prime}$, masih terdapat noise hal ini dikarenakan terjadi ambiguitas dari intensitas warna yang dapat ditentukan.

Proses Blob filtering bertujuan untuk menyempurnakan blob yang berada pada $f$ '. Hasil dari proses Blob filtering, adalah blob yang menjadi kandidate dari interest object $(\mathrm{cO})$. $\mathrm{cO}$ inilah yang selanjutnya dibuatkan contour serta diproses pada contour filtering. Terakhir adalah proses object determining digunakan untuk menentukan interest object hasil dari object determining adalah vektor yang berisi corner dan ukuran objek.

\section{Object Sampling}

Object sampling dilakukan oleh setiap tim robot soccer pada saat persiapan sebelum dimulainya pertandingan. Proses ini merupakan bagian dari setting parameter untuk persiapan pertandingan robot soccer, dikarenakan situasi dan situasi lingkungan yang dinamis serta sangat berpengaruh pada kinerja robot itu sendiri. Tahapan yang diusulkan dari object sampling terbagi menjadi empat tahap utama yaitu seleksi area objek, konversi warna, menentukan range warna dari objek yang diamati dan proses kliping, sebagimana ditunjukan pada Gambar 2.

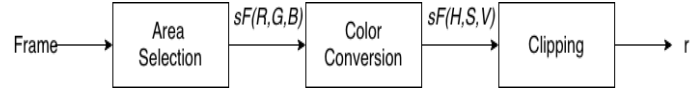

Gambar 2. Tahapan proses objek sampling

Tahap pertama adalah seleksi area interest object, dari tahap tersebut didapatlah matriks seperti yang ditunjukan pada persamaan 1. $(x, y)$ merupakan posisi corner dari proses seleksi, sedangkan $(w, h)$ merupakan ukuran lebar $(w)$ dan tinggi $(h)$ area dari interest object yang telah diseleksi. Setelah mendapatkan persamaan 1, selajutnya adalah memfokuskan pengamatan pada area tersebut. Proses penentuan area dinyatakan pada persamaan 2 .

$[x, y, w, h]$

$s F=\left[\begin{array}{ccc}(x, y) & \cdots & (x, y+w) \\ \vdots & \ddots & \vdots \\ (x+h, y) & \cdots & (x+h, y+w)\end{array}\right]$

$s F$ merupakan area interest object dengan struktur warna RGB (Red, Green, Blue) hasil dari pengindraan oleh kamera. Proses konversi kedalam struktur warna HSV (Hue, Saturation, Value) dilakukan pada $s F$, karena struktur warna HSV diyakini lebih efektif dalam membedakan tingkat iluminasi yang didapat dari pengaruh lingkungan. Selanjutnya frame dengan struktur warna HSV diproses dan dicari nilai minimum dan maksimum dari setiap layer-nya. Untuk mendapatkan nilai yang ril dan absolute, maka dilakukan proses kliping. Proses kliping ini dimaksudkan level nilai dari HSV yang didapatkan tidak keluar dari range 8 bit. Persamaan dari proses kliping ditunjukkan pada persamaan 3 dan 4 . Hasil dari proses object sampling ini adalah vector dari range level pixel HSV, ditunjukkan pada persamaan 5 .

$$
\min (h, s, v)=\left\{\begin{array}{c}
0, \min (h, s, v)<0 \\
\min (h, s, v)
\end{array}\right.
$$




$$
\begin{aligned}
& \max (h, s, v)=\left\{\begin{array}{c}
255, \max (h, s, v)>0 \\
\max (h, s, v)
\end{array}\right. \\
& r=[\min (h, s, v) \cap \max (h, s, v)]
\end{aligned}
$$

\section{Color filtering}

Proses color filtering dilakukan secara real-time oleh program. Prinsip dasar dari proses ini adalah melakukan penyaringan warna dari interest object yang telah ditentukan dalam proses object sampling. Proses color filtering dinyatakan pada persamaan 6 .

$\mathrm{f}^{\prime}=\left\{\begin{array}{c}255, r[0]<F(\mathrm{x}, \mathrm{y})<r[1] \\ 0\end{array}\right.$

$f^{\prime}$ merupakan hasil dari proses color filtering, yang berupa matriks dua dimensi (2D), sedangkan $F$ merupakan frame original yang ditangkap oleh pengindaraan kamera. Proses ini memfilter level pixel dari frame original, dimana jika nilai level pixel berada pada range minimum dan maksimum yang tersimpan pada $r$, maka diset nilai level pixel pada maksimum dan sebaliknya.

\section{Blob Filtering}

Proses blob filtering merupakan proses untuk memperbaiki kondisi blob. Dalam proses blob filtering digunakan dua filter yaitu menghapus noise dari blob dengan prinsip kerja erosi diikuti dengan dilasi dan melengkapi blob secara dilasi yang setelahnya diikuti erosi. Dua filter ini biasa disebut dengan morfologi, morphological open dan morphological close. Proses dari filter morfogi ini adalah menggunakan kernel 2D yang kemudian dilakukan scan pada f' dengan prinsip kerja konvolusi [16].

\section{Contour Filtering}

Proses contour filtering bertujuan untuk mencari daerah kandidate interest object. Proses contour filtering terbagi menjadi dua tahap yaitu pencarian contour dan seleksi contour. Tahap pencarian contour mengadopsi pada algoritma pencarian kontur [17] yaitu dengan menentukan ketetanggan dari batas objek. Digunakan kernel 8 ketetanggan dengan ukuran 3x3. Kemudian kernel tersebut diberjalan dari kanan atas menuju kiri bawah sebagimana proses konvolusi. Kemudian setelah mendapat semua kontur dari kandidate objek maka untuk menentukan interest object maka diambil area kontur yang maksimal.

\section{Object Determining}

Setelah mendapatkan kandidat interest object $(\mathrm{cO})$ hasil dari proses contour filtering selanjutnya adalah menentukan objek yang diamati dengan menambahkan boundary untuk objek, dengan perumusan sebagimana ditunjukan pada persamaan 7 .

$o B=\left[\begin{array}{ccc}(r, c) & \cdots & (r, c+w) \\ \vdots & \ddots & \vdots \\ (r+h, c) & \cdots & (r+h, c+w)\end{array}\right]$

Dimana $o B$ adalah boundary dari objek, $(\mathrm{r}, \mathrm{c})$ merupakan posisi dari boundary corner. Sedangkan $(w, h)$ merupakan ukuran lebar $(w)$ dan tinggi $(h)$ dari boundary objek.

\section{Hasil Dan Pembahasan}

Percobaan dari penelitian ini menggunakan dua belas video yang diambil langsung pada saat perlombaan robot soccer. Jumlah video yang diujikan sebanyak 12 video dengan total frame sebanyak 78.794 frame.
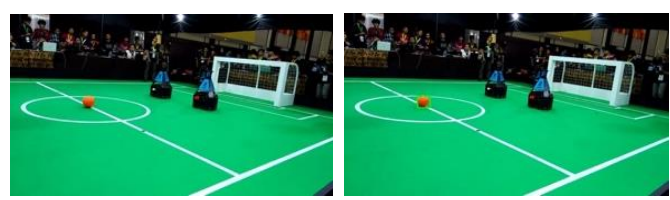

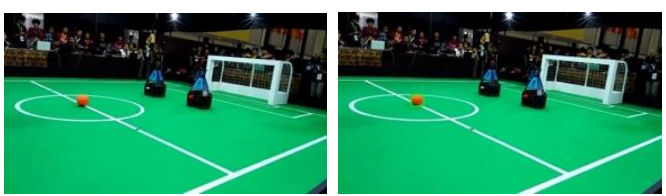

Gambar 3. Hasil deteksi bola oleh sistem yang diusulkan

Hasil yang didapat dari percobaan tersebut adalah cukup efektif dalam mendeteksi bola, dengan recall mencapai $90,69 \%$, tabel percobaan dapat dilihat pada tabel 1. Recall didapat dari True Positive (TP) dibagi dengan True Positive (TP) ditambah dengan False Negative $(\mathrm{FN})$.

Tabel 1. Hasil percobaan

\begin{tabular}{crr}
\hline \multicolumn{2}{c}{ Nama } & \multicolumn{2}{c}{ Jumlah } \\
No Video & Frame & \multicolumn{1}{c}{ Recall } \\
\hline 1 video1.mp4 & 3249 & $98,85 \%$ \\
2 video2.mp4 & 5751 & $100,00 \%$ \\
3 video3.mp4 & 5750 & $99,89 \%$ \\
4 video4.mp4 & 2762 & $98,19 \%$ \\
5 video5.mp4 & 19846 & $99,15 \%$ \\
6 video6.mp4 & 5804 & $99,96 \%$ \\
7 video7.mp4 & 4237 & $89,45 \%$ \\
8 video8.mp4 & 9348 & $60,38 \%$ \\
9 video9.mp4 & 9776 & $95,62 \%$ \\
10 video10.mp4 & 6593 & $65,57 \%$ \\
11 video11.mp4 & 4725 & $81,20 \%$ \\
12 video12.mp4 & 953 & $100,00 \%$ \\
\hline Total & 78794 & $90,69 \%$ \\
\hline
\end{tabular}

\section{Kesimpulan}

Pada penelitian ini diperoleh tahapan proses dari metode pendeteksian bola yang dapat diterapkan pada robot soccer. Penelitian ini mengusulkan lima tahap pendeteksian bola yaitu Object Sampling, Color Filtering, Blob Filtering, Contour Filtering, dan Object Determining. object sampling merupakan proses menentukan interest object dari sistem yang diamati. color filtering merupakan proses penentuan kandidat dari interest object, dengan cara memfilter warna. Setalah itu dilakukan proses blob filtering untuk memperbaik blob dan menghapus noise. Hasil hasil blob filtering diproses contour filtering dan ditentukan lokasi objek pada frame original. Dari hasil percobaan yang dilakukan didapat nilai recall sebesar $90,69 \%$.

\section{Daftar Pustaka}

[1] Pérez, L., Rodríguez, Í., Rodríguez, N., Usamentiaga, R., \& García, D. F. (2016). Robot guidance using machine vision techniques in industrial environments: A comparative review. Sensors (Switzerland), 16(3), 335. https://doi.org/10.3390/s16030335

[2] Holz, D., Genter, K., Saad, M., \& Stryk, O. von. (2019). RoboCup 2018: Robot World Cup XXII (Vol. 11374). Springer.https://doi.org/10.1007\%2F 978-3-030-27544-0

[3] Henning, K., Wolfgang, W., \& Johannes, H. (2013). Recommendations for implementing the strategic initiative INDUSTRIE 4.0. Final Report of the Industrie 4.0 WG, (acatech - National Academy of Science and Engineering), 82. https://doi.org/10.13140/RG.2.1.1205 .8966

[4] Alenyà, G., Foix, S., \& Torras, C. (2014). ToF cameras for active vision in robotics. Sensors and Actuators A: Physical, 218, 10-22.

[5] Nadarajah, S., \& Sundaraj, K. (2015). Vision in robot soccer: a review. Artificial Intelligence Review, 44(3), 289-310.

[6] Oliveira, J., Farçoni, L., Pinto, A., Lang, R., Silva, I., \& Romero, R. (2017). A review on locomotion systems for RoboCup rescue league robots. In Robot World Cup (pp. 265276). 
[7] Mehmood, T., Hashmi, U., Akhter, A., \& Ajmal, A. (2015). Techniques and approaches in Robocup@ HomeA review. In 2015 International Conference on Information and Communication Technologies (ICICT) (pp. 1-6).

[8] Zug, S., Niemüller, T., Hochgeschwender, N., Seidensticker, K., Seidel, M., Friedrich, T., Ferrein, A. (2016). An Integration Challenge to Bridge the Gap Among IndustryInspired RoboCup Leagues. In RoboCup.

[9] Rahman, A., \& Widodo, N. S. (2013). Colored Ball Position Tracking Method for Goalkeeper Humanoid Robot Soccer. Telkomnika, 11(1), 11.

[10] Treptow, A., \& Zell, A. (2004). Realtime object tracking for soccer-robots without color information. Robotics and Autonomous Systems, 48(1), 4148.

[11] Bader, M., Albero, M., Sablatnig, R., Simó, J. E., Benet, G., Novak, G., \& Blanes, F. (2006). Embedded realtime ball detection unit for the yabiro biped robot. In 2006 International Workshop on Intelligent Solutions in Embedded Systems (pp. 1-9).

[12] Shah, S. S. A., Khalil, M. A., Shah, S. I., \& Khan, U. S. (2018). Ball Detection and Tracking Through Image Processing Using Embedded Systems. In 2018 IEEE 21st
International Multi-Topic Conference (INMIC) (pp. 1-5).

[13] Gabriel, E., Schramm, H., \& Meyer, C. (2017). Analysis of the discriminative generalized Hough transform for pedestrian detection. In International Conference on Image Analysis and Processing (pp. 104115).

[14] Li, J., Xiao, J., \& Xu, S. (2017). Positioning method for robot soccer based on Kalman filter. In 2017 13th IEEE International Conference on Control \& Automation (ICCA) (pp. 892-897).

[15] Vijayarani, S., \& Vinupriya, M. (2013). Performance analysis of canny and sobel edge detection algorithms in image mining. International Journal of Innovative Research in Computer and Communication Engineering, 1(8), 1760-1767.

[16] Serra, J., \& Vincent, L. (1992). An overview of morphological filtering. Circuits, Systems and Signal Processing, 11(1), 47-108.

[17] Sklansky, J. (1982). Finding the convex hull of a simple polygon. Pattern Recognition Letters, 1(2), 79-83. 